\title{
Teaching Design to First-Year Engineering Students
}

\author{
Michael McGuire, Kin Fun Li, and Fayez Gebali \\ Electrical and Computer Engineering, University of Victoria \\ mmcguire@uvic.ca,kinli@uvic.ca, fayez@uvic.ca
}

\begin{abstract}
Design is associated with the invention, planning and building a product. Engineering design, in particular, takes considerable effort, skills, and integration of knowledge; hence, it is difficult to teach freshmen this subject since they have not possessed or developed the proper skill set yet. The Faculty of Engineering at the University of Victoria has been teaching engineering design (in two successive courses) to all first-year engineering students. In addition to attending plenary lectures, student teams are working on competitive projects in the laboratory, while participating in highly integrated communication modules. In this work, we discuss the curricula of these design courses, model of delivery and share our experience for the past three years.
\end{abstract}

Keywords: engineering education, teaching design, design project, first-year curriculum.

\section{INTRODUCTION}

Educating engineers is a particularly hard problem as modern engineering programs are expected to include instruction in mathematics, science, communications, project management and design [1]. Project-based learning is considered one of the best ways of providing these skills as this method of presenting material increases the students' engagement and allows the students to apply the newly acquired skills to true engineering problems [2] [3] [4]. In the Faculty of Engineering at the University of Victoria, we have introduced two project-based courses in first year, ENGR110 and ENGR120, to improve student retention and provide our students with a better understanding of actual engineering practice. The purpose of this paper is provide a description of these first year design project courses and what has been learned during the teaching of these courses.

Since these courses are offered in the first two terms of most of our students' university education, we have little control over their prior knowledge. In addition, our students come from many backgrounds. We have students from First Nations communities, international students, and English as a Second Language (ESL) students which often have difficulty transitioning to the university environment. Below, we will discuss some of the methods we are trying to allow these students to work in our project-based courses.

Section 2 contains a description of the project course at the Faculty of Engineering at the University of Victoria. Section 3 contains a description of the difficulties and main issues when running the course. A brief survey of first-year design courses at other Canadian universities is given in Section 4. Section 5 describes what conclusions are drawn from the experiences of administering and executing the design project.

\section{FIRST YEAR PROJECT COURSE DESCRIPTION}

The University of Victoria has two first year courses which teach design: ENGR110 and ENGR120. Both of these courses are taught jointly by instructors from the Faculty of Engineering and the Department of English. Before the introduction of these courses, it was found that the motivation of our students to learn the communications skills was low; several of our students mistakenly believed that communications were somehow less important than technical skills. By combining these courses, communications skills are presented in the context of technical reports, project proposals, status reports, and other types of communications that engineers will need to produce when they are conducting design during their careers. We will provide more information on these courses below.

\subsection{Description of the ENGR110 Course}

The ENGR110 course is the first design course that the students encounter. During this course the students are given instruction in academic writing and basic design skills. The communications portions the basics of research and essay writing sufficient for the students to complete other university courses. The basic design skills taught include teamwork, handling interpersonal conflicts in the workplace, and project management. The students learn these skills while competing several short projects. Examples of projects completed are building a paper platform capable of holding a person's weight with a 
competition to see which team can create the tallest platform, and design a food cart. The students complete these projects in groups of three with the team membership changing between projects. The last project is obtained from an industrial partner. At the completion of this course, the students will have the basic design skills and teamwork skills needed for the ENGR120 project course.

\subsection{Description of the ENGR120 Course}

During completion of this course, the students complete a longer project and learn the basics of technical writing. The communications portions of this course covers the basics of technical writing such as research, proposal writing, and the proper format of technical reports.

During the design portion of the course, the students are provided with some basic robotics knowledge and then given a two month robotics design project. Since the students have very limited prior technical knowledge, this courses gives them some basic instruction on electrical circuits, computer programming, basic control theory, and software engineering. The robotic project is structured so that the students can exercise some creativity in their designs and is large enough that the students must use proper design methodology in order to successfully complete this project.

2.2.1 Basic Technical Instruction. Basic technical instruction is required as part of the ENGR120 course as not all of the first year students have the same educational background. For example, some of our students have extensive programming experience while some students enter ENGR120 with only a single introductory computer science class. The students' experience with electrical circuits is also varied. The topics covered during this instruction include:

1. Basic computer programming. The students are instructed on the basics of $\mathrm{C}$ programming. This instruction is provided in evening tutorial classes to help students with limited prior computer science exposure.

2. Basic real time programming. The project involves programming a small embedded controller which requires a different programming style than the desktop application programming that most introductory computer science courses provide. This course teaches basic real time programming using finite state machines.

3. Basic electronic circuits. This consists of instruction on Ohm's law and how it can be used to analyze variable resistance sensors such as photoconductors and pressure sensors. While the basic high school Physics courses required for admission to the engineering program should have covered these topics, we have found that many of the students lack this prior knowledge.
4. Basic non-linear circuits. The students are instructed on the use of light emitting diodes (LEDs), phototransistors, and the use of Bipolar Junction Transistors (BJTs). The course shows how simple circuits can be used to perform simple tasks. For example, it is demonstrated how to use an infrared phototransistor combined with an BJT and LED to create a circuit which turns on a standard red LED light when the IR phototransistor detects light as shown in Figure 1.

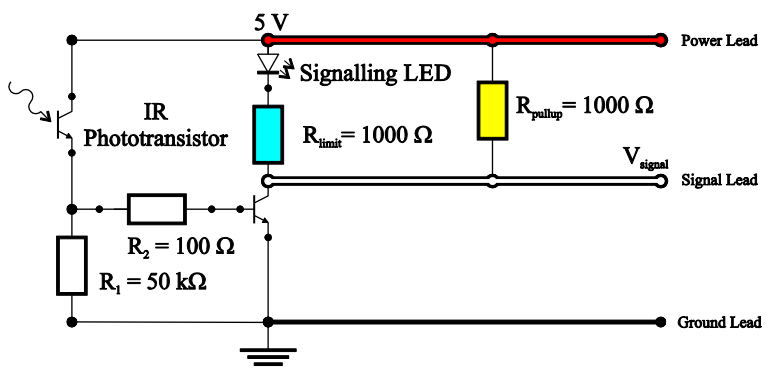

Figure 1: Basic IR Detector

5. Basic mechanical knowledge. The students are instructed in how to employ gears to allow a lower torque DC motor to create higher torque capable of lifting substantial weight.

6. Project management and design process knowledge. In addition to the technical knowledge described above, students are also given instruction on project management, and design process. This course extends the design process and project management material covered in ENGR110 with a discussion of the special difficulties of multidisciplinary designs consisting of mechanical, electrical hardware, and software. Integration testing and proper testing methodologies are introduced.

After completion of these lessons, the students have the basic knowledge to complete the main course project.

2.2.2 Description of ENGR120 Project. The ENGR120 project simulates the design of a prototype robot to clean a nuclear reactor after a major accident. For this application, a robot is needed which can enter the nuclear reactor core and perform a repair with a minimum amount of remote control. The students are asked to pretend that they are working for an engineering firm which is competing to build this robot. To this end, they are being asked to build a prototype robot which can autonomously perform a simple search and deployment task within an arena.

The test arena is shown in Figure 2. The designed robot must be capable of picking up a target located on a beacon placed within the arena. The beacon is shown in Figure 3.

The students are asked to design a target object which is placed on top of the beacon. The beacon emits infrared 
light. The robot must properly conduct the following operations:

1. Find the beacon within the arena.

2. Remove the target object from the beacon without hitting or moving the beacon.

3. Move to the edge of the arena without hitting the beacon or ramming roughly into the walls.

4. Drop the target object outside of the arena.

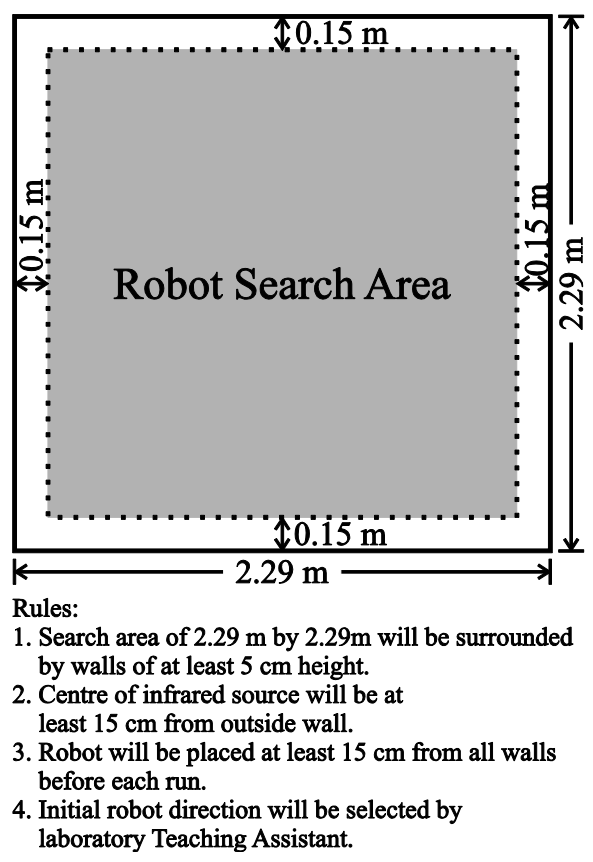

Figure 2: Robot Project Arena

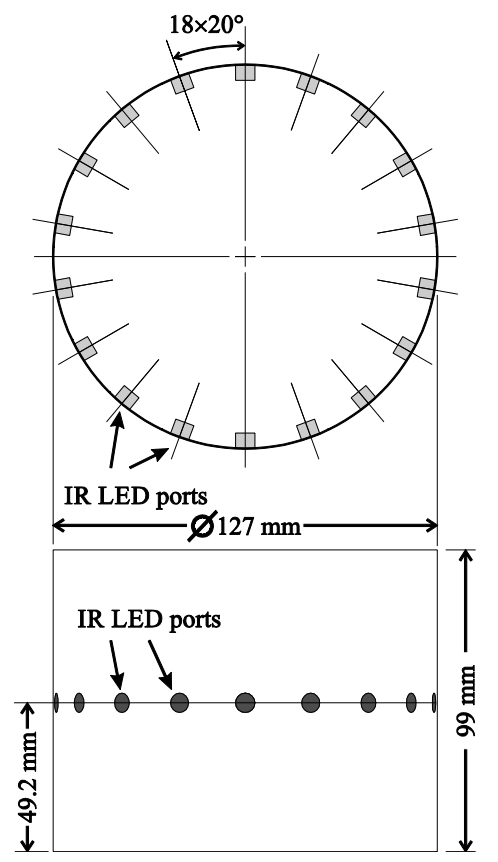

Figure 3: Target Beacon for ENGR120 Project
The robots are marked based on successful completion of these tasks with bonus marks for lower times to complete the tasks and creativity in the design of the robot or target object. The students build their robots in groups of three or four. The materials given to the students consist of a VEX robotics kit which structural, mechanical, and control components. The students must build their own infrared sensors using phototransistors, resistors, and BJT transistors from the template designs such as that described above.

There are four milestones during project completion when the students are marked. In Milestone 1, the students hand in sketches of possible designs for their robots with some details of the target object, location of sensors on the robot, and how the robot's locomotion systems will operate. For Milestone 2, the robots' mechanical systems are evaluation: locomotion systems, turning mechanism, and the mechanism which will pick up and drop the target object. In Milestone 3, the sensors of the robots are evaluated. The students must demonstrate that their robot is able to find the direction to the beacon, detect when the robot is at the proper orientation and distance from the target object for pickup, and detect when the robot is properly positioned to drop the target object outside of the arena. In Milestone 4, the full operation of the robot is evaluated.

\section{Major Issues When Running Design Courses}

The main issues encountered when running this project course were handling the diverse backgrounds/needs of the students, management of teaching assistant resources, professor engagement, and project management. Each of these issues is discussed in more detail below.

\subsection{Handling Student Diversity}

Students entering first year engineering in Canada come from many backgrounds: Canadian high schools and colleges; foreign schools and colleges; and technical schools/careers for the older students. The technical and communications skills vary greatly over the enrolled students. The differences in prior technical knowledge is partially addressed by the basic technical instruction described above. Additional tutorial sections where students needed extra instruction were originally proposed but the students' heavy workload prevented them from attending. The best solution was found to be encouraging students to consult with the teaching assistants about issues that they are having difficulty with. More details about this will be given in the next section.

A greater difficulty was preventing the students from forming unnecessary cliques such as ex-Canadian high schools students and foreign-origin students which do not communicate effectively with each other. The course and 
lab instructors made sure to emphasize to the students that engineering practice enjoys a great amount of diversity in its practitioners where having a technical staff base with more backgrounds is advantageous.

The University of Victoria has many engineering programs such as electrical and computer engineering, software engineering, mechanical engineering, civil engineering, and biomedical engineering. To maximize student engagement it is useful to have a project which contains elements which will inspire students intending to go into any of these fields later. The robotics project clearly has elements that are immediately useful for mechanical, electrical and software engineers. It is important for the instructor to highlight those points which are relevant to the other branches such as biomedical engineering and civil engineering. For example, during the course lectures the instructor brings up that design and implementing sensors such as the infrared sensors that the students are building as part of the robot is an important part of biomedical engineering. The instructor also describes how the structural design of the robot, ensuring that the robot can lift the target object off of the beacon and over the arena walls has the same basis as structural engineering in civil engineering practice. The basic concept of iterative design process including implementation, testing and revision is common across all fields of engineering in one form or another.

One issue is that students intending to go into one particular branch of engineering tend to want to join each other's team, leading to work terms with less technical diversity than desired. For example, a team consisting entirely of software engineering students may have difficulty with the mechanical portion of the design. We tried for one offering of the course having the instructors pick the teams. This gave the desired technical diversity but increased the amount of effort needed to handle failed team relations. Further work is needed to resolve this issue.

\subsection{Management of Teaching Assistants}

Design and project courses require high quality teaching assistants, particularly for lower year courses [5]. The multidisciplinary nature of the project requires the teaching assistants to be able to provide direction on circuits, mechanical design, and software programming. As this is a lower year course, the students' questions are usually quite basic. The teaching assistants must sometimes provide assistance with students who need help to troubleshoot or debug a system which requires creativity and experience. For example, many students encountered VEX controllers which seemed to be sending no signals to their attached motors despite all of the debugging displays indicating normal operation. The root cause of this problem was that the students' design was stalling the motor which caused the motor controller within the VEX controller to overheat. In this case, the controller disconnects the motor from the power supply until the temperature returns to normal. To diagnose this problem, the teaching assistant needed to have some experience working the motor controllers and the standard safety systems and know what conditions to look for.

The ENGR120 course had more than 300 students which precludes the professor in-charge of the course from performing all of the marking. As with all courses, it is important to keep the marking consistent between teaching assistances. For the milestones, the students perform demonstrations of the robots as well as hand in material for grading. To keep the marking of demonstrations consistent, a hierarchal system of teaching assistants is used where 8 junior teaching assistants report to two senior teaching assistants. The professor provides instruction to all teaching assistants on how marking is to be performed but the teaching assistants observe the majority of demonstration marking and by consulting with each other about exceptional cases provide extra direction to the junior teaching assistants as needed to keep the grading consistent.

\subsection{Professor Engagement}

A design course requires more time commitment from a professor than the standard technical course. The professor teaching this course must be prepared to be continually listen to the comments from his or her students to determine what the current issues are for the students, and providing marking guidance for teaching assistants. While this workload can be reduced by reusing the project for multiple offering of this course, in the Internet age students have access to many of the materials produced by previous students. It has been noted for our course, that if the same project is reused, the amount of variation in the designs is reduced with more students reproducing the 'known good' designs which performed well in the previous course offerings. Therefore, to maintain the creativity required by the students it is recommended that the project be updated with at least some significant changes each year to prevent copying of previous designs from succeeding without at least some adaptation.

\subsection{Student Project Management}

Despite the instruction given in the ENGR110 and at the beginning of the ENGR120 classes, many students still have difficulty with managing their time and team resources to complete the project. Most of these difficulties arise from the students' inexperience with working on large scale projects and working in teams. In particular, many first year students are still learning how to schedule their own activities and thus have difficulty 
balancing the time studying for other classes and working on the project. While upper year students are adept are at dividing their time between assignments based on their mark distributions, many first year students have not acquired these skills yet. The teaching assistants and professor must continuously remind these students about the deadlines and the proportion of grades allocated to the presentations and submissions.

The teaching staff for these courses must also be prepared in dealing with students who have issues dealing with people with different backgrounds. For example, many students from Canadian high schools are not prepared for dealing with students from different cultural backgrounds in a team setting. The teaching assistants must be vigilant in ensuring that teams allow everyone to make a contribution. The experience at the University of Victoria is that if potential team problems are caught early in the course during the early labs, most multicultural teams are able to function effectively for the long project.

\subsection{Design Courses at Other Institutions}

We have been monitoring what other Canadian engineering schools offer their first-year students since the inception of our design project courses.

At McMaster, an engineering design and graphics course that integrates graphics and communication associated with a product is offered. A similar offering can be found at Simon Fraser, which focuses on graphical communication in the context of engineering design.

Students at Memorial have to work in teams to design a robotic vehicle during the last few weeks of the term. No details could be found but this is the closest to what we are doing. Similarly, an engineering design course at Guelph also requires students to attain several milestones in a project (in 2011, a robot to perform some tasks autonomously. At Calgary, a course based on engineering design and communication, similar to ours, gives students the opportunity to learn design through a sequence of smaller projects.

New Brunswick has a course that requires students to work on a "real engineering design project for the local community in a simulated engineering consulting environment." A similar course that requires students to work with clients within the local community is offered at Queen's. Though, at both New Brunswick and Regina, many students are in competitions to design and build a Rube Goldberg machine.

At the University of Toronto, all first year engineering students take two design courses. Both courses address practical design challenges with I deals with on-campus projects while II deals with communities in the City of Toronto.

Introduction to design and innovation studio is the approach taken at Western Ontario. A team of instructors is responsible for the various studio components. The course is also tightly coupled with the CEAB attributes. A similar course focusing mainly on design process is offered at Windsor.

York offers an engineering design course that deals with constraints such as economic, safety, and social. Communication is an important focus but it does not appear that there is a hands-on project.

Students at Carleton are exposed to the design process and are required to use modeling software to illustrate some 'original invention'. Dalhousie offers a similar course emphasizing 3D visualization and reading/drafting of engineering drawings.

At $\underline{\mathrm{UBC}}$, a large number of hands-on design projects had been available to students in their first year desogm course. In the past years, this course has evolved into a more organized prototyping lab and requires students to build a rubber band satellite launcher (2015).

In 2013 when ENGR120 was launched, no information on a common first-year engineering design course at these institutions could be found: Alberta, Concordia, Lakehead, McGill, Ottawa, Ryerson, and Waterloo.

\subsection{Conclusions}

The project courses have been found to improve the experience of the first year engineering students at the University of Victoria. There are, however, several issues that must be addressed when presenting project courses to first year students. The instructors must take into account the different backgrounds in terms of culture and education of the students and the different capabilities of the students in terms of managing their own time and working with others.

\section{References}

[1] J. E. Froyd, P. C. Wankat and K. A. Smith, "Five major shifts in 100 years of engineering education," Proceedings of the IEEE 100, vol. 100, no. Special Centennial Issue, pp. 1344-1360, 2012.

[2] J. Bazylak and P. Wild, "Best Practices Review of First-Year Engineering Design Education," in Proceedings of the Canadian Engineering Education Association, 2011.

[3] C. L. Dym, A. M. Agogino, O. Eris, D. D. Frey and L. J. Leifer, "Engineering Design Thinking,Teaching, and Learning," Journal of Engineering Education, no. January, pp. 103-120, 2005.

[4] T. Veltman and W. Rosehart, "Work in Progress - Design in First Year," in IEEE Frontiers in Education Conference (FIE), Washington, DC, 2010.

[5] J. S. Choi , "Being a Teaching Assistant (TA) in First Year Engineering Course: Perspectivess, Challenges, Rewards, and Recommendations," in Proceedings of the Canadian Engineering Education Association, 2013. 